\title{
Proceeding
}

Supplementary Issue: Rio 2016 Olympic Games Second Anniversary Special Edition. Olympic Studies Forum, 2-3 October 2018.

Federal University of Espirito Santo, (Vitória - Espirito Santo), Brazil

\section{Brazilian sailor at the Olympic Games of the 1950s}

\author{
CAROLINA FERNANDES DA SILVA ${ }^{1} \triangle$, JANICE ZARPELLON MAZO² \\ ${ }^{1}$ Sports Center, Federal University of Santa Catarina (UFSC), Florianópolis, Brazil \\ ${ }^{2}$ School of Physical Education, Federal University of Rio Grande do Sul (UFRGS), Porto Alegre, Brazil
}

\begin{abstract}
The present study aims to understand how the journey of the first southern Brazilian sailor to participate in the Olympic Games (OG) of the Modern Era occurred. To that end, the sources used were Brazilian newspapers, which were submitted to documentary analysis. Yachting, since the OG of 1900, has continued in all subsequent editions with an increasing number of countries participating in the disputes. Brazil's participation in this modality began in the 1936 OG. Brazilian Olympic athletes precursors of sailing were linked to clubs in Rio de Janeiro and São Paulo. Only in the editions of the OG of the 1950s, the Brazilian delegation will be composed of sailors from other Brazilian states. The southern Brazilian athlete Alfredo Jorge Ebling Bercht did his debut in 1952 and, in 1956, participated with his brother, Rolf Ebling Bercht. The sources revealed that the participation of Alfredo Ebling Bercht in the OG of the 1950s did not obtain prominence in the press of Rio Grande do Sul and was little mentioned in the one of Brazil, despite the trajectory of this sailor in regional and national competitions are followed conquests and these are valued and published by the newspapers. In addition, the trajectory of this sailor shows the disputes between modalities inside the confederations. Keywords: Olympism; Sailing; History.
\end{abstract}

\section{Cite this article as:}

Fernandes, C., \& Zarpellon, J. (2019). Brazilian sailor at the Olympic Games of the 1950s (in Portuguese). Journal of Human Sport and Exercise, 14(3proc), S294-S300. doi:https://doi.org/10.14198//hse.2019.14.Proc3.02

Corresponding author. Deputado Antônio Edu Vieira Avenue, University Campus, Pantanal, CEP 88040-901, Florianópolis, Santa Catarina, Brazil. https://orcid.org/0000-0003-0026-1318

E-mail: carolina.f.s@ufsc.br

Supplementary Issue: Rio 2016 Olympic Games Second Anniversary Special Edition. Olympic Studies Forum, 2-3 October 2018. Federal University of Espírito Santo, (Vitória - Espírito Santo), Brazil.

JOURNAL OF HUMAN SPORT \& EXERCISE ISSN 1988-5202

(c) Faculty of Education. University of Alicante

doi:10.14198/jhse.2019.14.Proc3.02

S294 | 2019| Proc3| VOLUME 14

C 2019 University of Alicante 


\section{INTRODUÇÃO}

A vela, também denominada de iatismo ${ }^{1}$, foi um dos primeiros esportes a fazer parte dos Jogos Olímpicos (JO), estreando na edição de 1900, em Paris, na França. Para o Barão Pierre de Coubertin, idealizador dos JO da Era Moderna, esta era uma prática desafiadora por ter os fenômenos da natureza como mais um obstáculo a ser vencido. Coubertin proferiu: "Destaco também o instinto combativo de certos esportes que têm, no entanto, como característica peculiar o fato de que o homem parece permanecer mais ou menos passivo diante da força desencadeada e que às vezes não pode dominar" (Müller \& Todt, 2016, p. 135).

A vela está dentre os esportes que Bourdieu (1983) classifica como práticas de distinção, as quais servem de ocasião para acontecimentos eletivos. Tal prática estava atrelada aos interesses de Coubertin, um homem oriundo da elite francesa. Para Coubertin: "A massa terá os concursos e as festas da Exposição, enquanto nós organizaremos jogos para a elite: a elite entre os atletas, pouco numerosos, mas que abarca os melhores campeões do mundo; a elite entre os espectadores, homens e mulheres da sociedade [...]" (Müller \& Todt, 2016, p. 381). Assim, vai ao encontro da perspectiva de Vigarello (2005, p. 188) de que "cada esporte só revelava aspectos sociais opondo-se a outros esportes ou 'situando-se "em relação a outros". Nos JO de 1900, a vela foi inserida no rol dos esportes olímpicos e se manteve em todas as edições seguintes com um número cada vez mais significativo de países participando das disputas. Trata-se de um dos mais tradicionais esportes dos JO e a participação do Brasil nesta modalidade iniciou na edição de 1936, em Berlim, Alemanha. Desde então, prosperou a presença de velejadores brasileiros nas edições dos $\mathrm{JO}$ e a conquista de medalhas. Assinala-se que "a vela é a modalidade com o maior número de medalhas de ouro olímpicas na história do esporte do Brasil: sete. Ao todo, os velejadores brasileiros já conquistaram 18 medalhas em Jogos Olímpicos" (CBVELA, 2018, nov 16). As medalhas olímpicas foram conquistadas décadas após a fundação de clubes destinados a essa prática no Brasil. Os clubes de vela no estado do Rio Grande do Sul, foram instituídos na década de 1930 e, após duas décadas, nos anos 1950, velejadores sulrio-grandenses integraram a delegação brasileira nas competições de JO. Antes disso, os atletas olímpicos brasileiros, precursores da vela, estavam vinculados na sua maior parte aos clubes do Rio de Janeiro e São Paulo (COB, 2004).

$\mathrm{Na}$ edição dos JO de 1952, em Helsinque, na Finlândia, o atleta sul-rio-grandense Alfredo Jorge Ebling Bercht fez a sua estreia, e nos JO de 1956, em Melbourne, na Austrália, novamente participou das competições juntamente com o seu irmão, Rolf Ebling Bercht. Como a vela era um esporte de distinção, tais velejadores apresentavam capital simbólico que permitia a prática. Além de fazer parte do Clube Veleiros do Sul, o qual possuía uma rígida seleção de seus sócios, Alfredo Bercht tinha seu próprio barco, o modelo Sharpie Inca, bem como praticava outro esporte rotulado como de elite, o automobilismo (A primeira prova..., 1952, fev. 17). Ademais era empresário da indústria do vestuário (Edital de apresentação..., 1956, maio 30, p. 5) e, posteriormente foi dono de posto de gasolina. Logo, o seu irmão, Rolf Bercht foi professor dos cursos de Engenharia da Universidade Federal do Rio Grande do Sul (Obituário, 2012 apud Mazo, 2019). Além disso, destacou-se no ensino superior porque foi um dos primeiros professores a realizar um curso sobre programação de computadores, em 1961 . O percurso dele vai ao encontro da afirmação de Vigarello (2005): os proprietários de veleiros dispõem de mais capital cultural do que os donos de barco a motor, que possuem maior capital econômico.

Nos JO de 1952, Alfredo Bercht conquistou a nona colocação e na edição de 1956, obteve o $10^{\circ}$ lugar na classificação geral. Nesses eventos, a vela brasileira teve pouco destaque em relação ao atletismo e a

\footnotetext{
${ }_{1}$ Para o presente estudo, será utilizado o termo vela, por este ser o que identifica a modalidade olímpica.
} 
natação, que conquistaram medalhas de ouro e bronze, nas edições de 1952 e de 1956 (COB, 2004). No entanto, nos dias atuais, a vela é um dos esportes que mais conquistou medalhas nos JO para o Brasil, a saber: México 1968, Montreal 1976, Moscou 1980, Los Angeles 1984, Seul 1988, Atlanta 1996, Sydney 2000, Atenas 2004, Pequim 2008, Londres 2012, Rio de Janeiro 2016. A despeito da importância das medalhas conquistadas, entendemos que para avançar na compreensão do cenário dos esportes olímpicos no país, se faz necessário reconstituir os caminhos trilhados pelos atletas que não conquistaram medalhas nos JO, mas que fazem parte da memória esportiva brasileira. Talvez, esses atletas são esquecidos porque não subiram no pódio olímpico, mas deveriam ser lembrados uma vez que fazem parte da construção histórica do campo esportivo nacional. A partir dessa perspectiva, o presente estudo visa compreender como ocorreu a participação do velejador sul-rio-grandense Alfredo Bercht nos JO de 1952 e 1956.

\section{MATERIAIS E MÉTODOS}

Para fins deste estudo, as informações sobre Alfredo Bercht foram coletadas em jornais que circulavam no período, encontrados na Hemeroteca Digital da Biblioteca Nacional brasileira, a saber: Correio da Manhã, Diário de Notícias e Diário da Noite, do Rio de Janeiro. Além desses, também foram garimpadas reportagens em jornais do Rio Grande do Sul. Todavia das 97 reportagens encontradas sobre os Jogos Olímpicos, na década de 1950, em apenas quatro notícias foram citados os nomes de Alfredo Bercht e Rolf Bercht e nenhuma delas, surpreendentemente, mencionava a participação dos velejadores em JO. 0 corpus documental foi analisado a partir da técnica de análise documental e as informações foram cruzadas com a revisão de literatura e o contexto sociocultural do recorte temporal.

\section{RESULTADOS E DISCUSSÃO}

\section{O velejador olímpico em Helsinque (1952) e Melbourne (1956)}

As primeiras informações sobre o início das conquistas que levaram Alfredo Bercht até os JO de 1952 datam 0 ano de 1940, quando o Clube Veleiros do Sul, depois de receber atletas uruguaios, argentinos, paulistas e cariocas, para a regata de comemoração do Bicentenário de Porto Alegre organizou uma delegação para competir no Uruguai (Böhm \& Carvalho, 2001). Os anos posteriores foram de muitas vitórias para os irmãos Alfredo e Rolf Bercht, mas principalmente para Alfredo Bercht em diversas competições individuais (Regatas, 1944, jan. 21; Alfredo Bercht..., 1945, jul. 21; Regata de Veleiros Brasil, 1946, nov 6). A sequência de conquistas dos irmãos Bercht iniciou com IV Copa Miraguaya, em 16 de dezembro de 1944, classe Sharpie $12 \mathrm{~m}$, em comemoração ao $10^{\circ}$ aniversário da fundação do Clube Veleiros do Sul. Contudo, Alfredo Bercht foi chamado para compor a equipe de vela olímpica para os JO de Helsinque quando se tornou campeão brasileiro em 1950, no V Campeonato Brasileiro de Barcos a Vela (Resultados do V Campeonato..., 1950, nov 17, p. 5). 0 embarque da delegação brasileira para Helsinque foi noticiado pelo jornal Diário da Noite, o qual mencionou as equipes de atletismo, polo aquático, saltos e futebol. $O$ jornal registra que a Confederação Brasileira de Desportos (CBD) custeou a viagem da seleção olímpica de futebol e dos nadadores Fernando Pavão e João Gonçalves, pois eram possíveis medalhistas nos JO e em razão do Comitê Olímpico do Brasil (COB) ter declarado que não dispunha de verba para incluí-los na delegação. Todavia, na reportagem, sobressai a seguinte crítica: "importa dizer que vinte e duas pessoas estranhas devem se beneficiar com as vantagens do passaporte olímpico" (Irão também à Helsinque..., 1952, jul. 2, p. 8). Alfredo Bercht foi mencionado apenas na lista dos 148 componentes do grupo que deixou o Brasil em direção à Finlândia (Irão também à Helsinque..., 1952, jul. 2). Ele partiu do Brasil apenas no dia 10 de julho de 1952, juntamente com os últimos atletas que ficaram no país aguardando a viagem (Partem os últimos..., 1952, jul. 10). 
Após o retorno dos $\mathrm{JO}$ de Helsinque, Alfredo Bercht começou a promover palestras sobre sua participação no evento, como também sobre regras internacionais de regata visando a formação de um corpo de juízes de regata (Böhm \& Carvalho, 2001). A realização de eventos com Alfredo Bercht demonstra um reconhecimento do Clube Veleiros do Sul quanto a sua trajetória, situação diferente dos jornais brasileiros, visto que não foram encontradas reportagens sobre seu retorno para o Brasil após os JO. Tais jornais destacaram apenas as medalhas conquistadas no evento. No ano seguinte aos JO de Helsinque, em 1953, Alfredo Bercht mantém-se na liderança no VI Campeonato Brasileiro Individual de Vela (Gaúchos campeões brasileiros..., 1953, nov 14) e ainda fez parte da equipe campeã no VI Campeonato Brasileiro de latismo (Gaúchos campeões de iatismo, 1953, nov 11). Os JO de Helsinque foram os primeiros passos na trajetória para Alfredo Bercht competir novamente em 1956, nos Jogos de Melbourne, desta vez com o irmão.

Os JO de Melbourne em 1956 inauguraram a era dos boicotes. Como se não bastassem os problemas externos, a situação interna no país não era das melhores, no que diz respeito à preparação e organização do evento. Um ano antes dos JO nenhuma obra cumpria o cronograma previsto para a sua conclusão, pois uma disputa entre o Governo Federal e a prefeitura de Melbourne atrasou a liberação dos recursos para 0 projeto olímpico. A situação só melhorou quando o Governo Federal repassou 4,5 milhões de dólares para - Comitê Organizador. Outro problema estava relacionado a determinação de quarentena de seis meses para a entrada de cavalos na Austrália, medida preventiva contra a epidemia de febre equina que se alastrava pelo mundo na época. De posse da informação de que o governo australiano não mudaria de posição sobre a entrada de cavalos no país, o Comitê Olímpico Internacional (COI) reuniu-se representantes de outros países, para achar uma solução para a situação. Nesse caminho, os presidentes da Federação Internacional Equestre e da Federação Internacional de Pentatlo, emitiram um comunicado de que fariam um esforço supremo para impedir a celebração dos JO na Austrália, e iriam designar para a sede dos mesmos um país que respeitasse a carta olímpica (Ainda..., 1954, maio 7). As autoridades sanitárias locais não abriram exceção para os cavalos que deveriam chegar para os $\mathrm{JO}$, e contrariando as normas, pela primeira vez 0 evento foi realizado em países diferentes, simultaneamente. A solução foi transferir cavalos e cavaleiros para Estocolmo, na Suécia (COB, 2004).

A Guerra Fria cada vez mais mexia com a imaginação do público que acompanhava os $\mathrm{JO}$, pois com a entrada da União Sovética nos JO de 1952, muitos torcedores norte-americanos esperavam que o evento fosse uma competiçao entre esses dois países, e que os demais ficariam a margem destes nas competições. Estas questões iam de encontro às declarações do Presidente de $\mathrm{COl}$ e de outros dirigentes olímpicos, de que os $\mathrm{JO}$ constituem competições individuais e não luta de países. Nesse sentido a soma do número de medalhas feita pela imprensa também começou a incomodar o $\mathrm{COI}$, que declarou: "Nenhum país ganha os Jogos Olímpicos, os vários esportistas é que ganham individualmente nas suas modalidades, e só" (Não há..., 1956, maio 25). Para os JO de Melbourne, o Brasil levou uma delegação de 48 atletas, com apenas uma mulher, e destes três eram representantes do Rio Grande do Sul: os irmãos Alfredo Jorge Ebling Bercht e Rolf Fernando Ebling Bercht na vela; e Breno Vignoli, primeiro atleta brasileiro participando da competição de pentatlo moderno em JO.

O passaporte olímpico de Alfredo Bercht foi carimbado para os JO de Melbourne, no dia 28 de abril de 1956, quando acabam as eliminatórias de vela e ele sagrou-se campeão "com 4 primeiros lugares e um segundo, totalizando 4.500 pontos" (Eliminatória para as olímpiadas, 1956, abr. 28, p. 7). Com esta vitória e a conquista do VI Campeonato Brasileiro de Snipes, o jornal O Poti declara que Alfredo Bercht e Eduardo Jacobsen "são indiscutivelmente os melhores do Brasil na atualidade" (Novamente vitoriosos os gaúchos..., 1956, abr. 18, p. 5). Entretanto, a viagem para Melbourne não aconteceu sem que obstáculos fossem vencidos. A Confederação Brasileira de Vela e Motor (CBVM), em 27 de junho de 1956, teve que decidir 
qual tipo de barco enviaria para competir nos JO de 1956, visto que não poderia enviar um barco para cada categoria, pois o COB determinou que só fosse um barco com no máximo três tripulantes. De tal modo, a opção foi pelo Sharpie (dois tripulantes) e um da classe Finn (um tripulante). A classe Star, que também é de dois tripulantes e tinha cariocas como seus representantes, entrou com recurso, o qual foi publicado na integra no jornal Correio da Manhã (O recurso da..., 1956, ago. 12). Todavia, a CBVM manteve a decisão, a qual foi tomada "levando em consideração que os indicados foram os primeiros a dar glórias internacionais ao iatismo brasileiro" (Kastrup, 1956, ago. 17, p. 3). Os jornais do Rio de Janeiro questionaram a escolha da classe Sharpie e defendiam que a representante brasileira deveria ser a classe Star, o que demonstra a competição que havia entre os estados fora do tempo e do espaço da disputa esportiva.

Um dos argumentos dos velejadores da classe Star foi de que o barco Sharpie não tinha as medidas oficiais para a competição (O recurso da..., 1956, ago. 12), o que fez a CBVM encomendar um novo barco no mesmo dia da reunião, segundo Kastrup (1956, ago. 17). No entanto, outra reportagem afirma que Alfredo Bercht utilizaria seu próprio barco, o Sharpie Inca e teria a responsabilidade de ser o patrão do barco (Teixeira Heizer, 1956, out 24). No mesmo texto, o autor (Teixeira Heizer, 1956, out 24) acredita que Alfredo Bercht "leva a grande responsabilidade de bem representar o Brasil na Olimpiada. Sua experiência e classe de grande e veterano veleiro levam-nos a acreditar que fará sucesso extraordinário nos Jogos Olímpicos de Melbourne" (Teixeira Heizer, 1956, out 24, p. 10). Desta vez, Alfredo Bercht faria dupla com seu irmão, Rolf Bercht, com quem já competia desde a década de 1940 . Eles ficaram em $10^{\circ}$ lugar na classificação geral (COB, 2004), uma posição atrás da edição anterior dos JO.

Na volta para o Brasil, o barco de Alfredo Bercht ficou preso na Alfândega, no Rio de Janeiro. O COB e CBMV foram culpados pela situação pela impressa sul-rio-grandense, porém as entidades não assumiram a responsabilidade, transferindo o encargo do ocorrido uma para a outra (Ameaçado de ir a..., 1958, abr. 10). Esta ocorrência apenas obteve a atenção dos jornais dois anos após o acontecimento dos $\mathrm{JO}$ e do retorno de Alfredo Bercht para o Brasil, quando o barco quase foi a leilão (Por representar o Brasil..., 1958, abr. 8). O Jornal dos Sports do Rio de Janeiro publicou uma reportagem que trouxe à tona o que estava acontecendo com o barco Inca, de propriedade do velejador e que competiu nos $\mathrm{JO}$, o qual ficou parado na Alfândega se deteriorando e sem manutenção. A mesma reportagem destaca os apelos sem sucesso do velejador aos dois órgãos responsáveis, CBVM e COB, os quais ganharam volume quando o mesmo aconteceu com outro velejador que representou o Brasil no Campeonato Mundial da Classe Snipe, em setembro de 1957, e também teve seu barco retido (Por representar o Brasil..., 1958, abr. 08). A atenção da imprensa surtiu resultado, pois repórteres foram buscar mais informações sobre 0 assunto com 0 responsável do $\mathrm{COB}$. Os repórteres indicaram o nome de quem havia perdido os documentos do barco Inca, que por isso estava sendo considerado barco estrangeiro, apesar de ter saído do Brasil. Depois de quatro dias da publicação da primeira reportagem sobre 0 assunto, o barco foi liberado, após uma declaração do cônsul da Austrália (Será liberado o barco..., 12/04/1958). Esta foi última participação de Alfredo Bercht em JO, no entanto, continuou competindo e foi campeão brasileiro nos anos de 1961 até 1965. Ainda, participou de uma competição internacional pelo mesmo clube e o velejador disputou competições até a década de 1980 (Flotilha, 2012). Diferentemente de Alfredo Bercht, após os JO de 1956, não foram encontrados registros de outras participações de Rolf Bercht em competições. Formado pela UFRGS, onde também foi professor no curso de Engenharia Elétrica da Escola de Engenharia, faleceu em Porto Alegre no dia 22 de setembro de 2012, aos 87 anos (Obituário, 2012 apud Mazo, 2019). 


\section{CONCLUSÃO}

O estudo evidenciou que, mesmo a vela estando presente nos JO desde a sua segunda edição (1900) fazendo parte da história esportiva do Brasil desde o início do século XX, este esporte não era notícia usual nos jornais. Diversas razões podem ter contribuído para isso como, por exemplo, a vela não haver conquistado o pódio olímpico, como ocorreu com outros esportes em edições posteriores. Todavia, Alfredo Bercht contribuiu com a propagação desse esporte através da participação em duas edições dos JO e por compartilhar suas aprendizagens por meio de palestras e cursos no retorno ao Rio Grande do Sul. Além disso, a trajetória do velejador encena as disputas travadas entre modalidades no interior das próprias entidades esportivas.

Por fim, ponto a se destacar, foi o empenho de Alfredo Bercht para a recuperação do barco Inca na Alfândega, problema que foi solucionado apenas quando a imprensa deu destaque para o drama vivido pelo velejador. Esse episódio demonstra que a imprensa (jornais) na época, já exercia certo poder no cenário nacional. Todavia, parece que a visibilidade do atleta olímpico brasileiro pela imprensa foi maior após os JO e devido ao acontecimento com seu barco.

\section{REFERÊNCIAS}

A primeira prova do campeonato gaúcho de automobilismo. (1952, fev 17). Jornal do Dia.

A transmissão dos Jogos Olímpicos. (1952, jul 01). Jornal do Dia, p. 1.

Ainda o problema das Olimpiadas. (1954, mai 7). Correio da Manhã, p. 11.

Ameçado de ir a leilão os barcos. (1958, abr 10). Correio da Manhã, pp. 1 - 2.

Alfredo Bercht e Orlando Coelho na liderança. (1945, jul 21). Diário de Notícias, p. 1.

Bourdieu, P. (1983). Como é possível ser esportivo? . In Questões de sociologia (pp. 33). Rio de Janeiro: Marco Zero.

COB - Comitê Olímpico Brasileiro. (2004). Sonho e conquista: o Brasil nos Jogos Olímpicos do Século $X X$. Rio de Janeiro.

Böhm, G., L., \& Carvalho, L. F. (2001). História do Veleiros do Sul Sociedade Náutica Desportiva: da fundação até a transferência da sede para o bairro Cristal. Porto Alegre: Editora da UFRGS.

CBVELA - Confederação Brasileira de Vela. Retrieved from http://www.cbvela.org.br/historia-da-vela/

Edital de apresentação de chapa. (1956, mai 30). Diário de Notícias.

Eliminatória para as Olimpíadas. (1956, abr 28). A noite, p. 1.

Flotilha. (20/02/2019). Retrieved from http://flotilha.blogspot.com.br/2012/11/inca-2000-um-tristefim.html

Gaúchos campeões brasileiros de latismo. (1953, nov 14). A noite, p. 1.

Gaúchos campeões de iatismo. (1953, nov 11). Diário da Manhã, p. 1.

Irão também à Helsinque Fernando Pavão e João Gonçalves. (1952, jul 02). Diário de Notícias, p. 1.

Kastrup, S. (1956, ago 17). Vela e Motor. Tribuna da Imprensa, p. 1.

Mazo, J. (2019). Banco de Dados de Obituários Esportivos - Anúncios Fúnebres e Religiosos do Jornal Zero Hora de Porto Alegre/RS. (in press).

Müller, N., \& Todt, N. (2015). Pierre de Coubertin (1863-1937), Olimpismo: seleção de textos. Lausanne: Comitê Internacional Pierre de Coubertin. https://doi.org/10.1093/ww/9780199540884.013.u207930

Novamente vitoriosos os gaúchos com Gabriel Gonçalves e Jacobsen Bercht empatados: $1^{\circ}$ lugar. (1956, abr 18). O Poti, p. 1.

Não há nas olimpíadas competição a competição de países. (1956, mai 25). Correio da Manhã, p. 1. O recurso da classe Star. (1956, ago 12). Correio da Manhã, p. 1. 
Partem os últimos elementos da delegação brasileira. (1952, jul 10). Diário de Notícias, p. 1.

Por representar o Brasil perderão seus barcos. (1958, abr 8). Jornal dos Sports, p. 1.

Regata de veleiros Brasil. (1946, nov 06). Correio da Manhã, p. 1.

Regatas. (1944, jan 21). Diário de Notícias, p. 1.

Resultados do V Campeonato Brasileiro de Barcos a Vela. (1950, nov 17). Diário da Noite, p. 1.

Será liberado o barco de Bercht. (1958, abr 12). Jornal dos Sports, p. 1.

Teixeira, \& Heizer. (1956, abr 24). Um notável veleiro gaúcho. Diário da Noite, p. 1.

Vigarello, G. (2005). Sistemas de esportes, esportes concorrentes. In: M. Lagrave (Ed.), Trabalhar com Bourdieu (pp. 10). Rio de Janeiro: Bertrand Brasil.

\section{(C) $(1) \Theta$}

This work is licensed under a Attribution-NonCommercial-NoDerivatives 4.0 International (CC BY-NC-ND 4.0). 